\title{
Sneaky snails and wasted worms: kleptoparasitism by Trichotropis cancellata (Mollusca, Gastropoda) on Serpula columbiana (Annelida, Polychaeta)
}

\author{
Erika V. Iyengar* \\ Department of Ecology and Evolutionary Biology, Corson Hall, Cornell University, Ithaca, New York 14853, USA
}

\begin{abstract}
Individuals of the marine snail Trichotropis cancellata can either suspension feed or steal food from tube-dwelling polychaete worm hosts (kleptoparasitism). Because kleptoparasitism is facultative in this case, the performance of both members can be evaluated separately and together. I used field experiments to compare the growth of suspension feeding snails with that of snails (either singly or in groups) on Serpula columbiana polychaete hosts. All sizes of $T$. cancellata grew more quickly (up to 18 times faster) when parasitizing $S$. columbiana than when restricted to suspension feeding. Kleptoparasitism provided a proportionally greater growth benefit for small and mediumsized snails than for larger ones, suggesting that smaller gastropods are more food-limited when suspension feeding. Fecundity was positively correlated with snail size, so the growth benefits of kleptoparasitism are likely to be selectively advantageous. Increasing numbers of medium-sized snails on a host reduced individual snail growth rates, suggesting competition for the worm's food. All snails were equally affected; there was not a superior competitor among medium-sized snails. Parasitism was experimentally demonstrated because serpulid worms grew their tubes more slowly when supporting parasitic snails and were increasingly negatively affected by additional medium-sized parasitic snails. Adding large parasitic snails did not exacerbate the negative impact on worm tube growth, so I concluded that a single large snail reduces worm hosts to their minimal rate of tube extension. Suspension feeding T. cancellata gain additional resources when they switch to kleptoparasitism.
\end{abstract}

KEY WORDS: Symbiosis · Kleptoparasitism $\cdot$ Growth rate

\section{INTRODUCTION}

Suspension feeding is common in the marine realm, performed by members of widely disparate taxa including polychaetes, anemones, bryozoans, brachiopods, bivalves, ascidians, fish and snails. Despite having evolved multiple times within the prosobranchs (Declerck 1995), suspension feeding remains a restricted feeding mode among marine gastropods. In the bivalves, a closely related group, suspension feed-

*Present address: Department of Biology, The College of Wooster, Wooster, Ohio 44691, USA.

Email: eiyengar@wooster.edu ing is the principal feeding strategy and suspension feeding bivalves are more species-rich than nonsuspension feeding ones. Why there are not more suspension feeding gastropods is puzzling.

Most suspension feeding gastropod adults supplement their diet, usually by grazing or deposit feeding (Declerck 1995). The marine snail Trichotropis cancellata, originally described as a suspension feeder (Yonge 1962), can steal food from tube-dwelling polychaete worms (Pernet \& Kohn 1998) by extending its pseudoproboscis between the feeding tentacles of the polychaete and into its mouth. Using cilia on the pseudoproboscis, the snail draws food from the suspension feeding worm's mouth. All size classes of snails in populations in the San Juan Islands, Washington, are pre- 
dominantly positioned at the opening of worm tubes (Iyengar 2002).

To determine whether this symbiotic interaction is a mutualism, parasitism, commensalism or amensalism, the benefits or costs experienced by each participant must be determined. Facultative symbiotic interactions are uniquely amenable to experimental manipulations. The performance of each symbiont within (as kleptoparasites) and outside (as independent feeders) the interaction, as well as the comparative benefits of each feeding mode, can be assessed. In laboratory experiments, Pernet \& Kohn (1998) showed that small (4.0 to $7.0 \mathrm{~mm}$ ) and large (17.0 to $23.0 \mathrm{~mm}$ ) Trichotropis cancellata grew faster as symbionts on Serpula columbiana polychaetes than as suspension feeders. By recording the presence or absence of egg capsules, they also demonstrated that symbiotic females were more likely to lay egg capsules than suspension feeding females (Pernet \& Kohn 1998). Laboratory experiments, however, can be subject to a number of unnatural conditions. This is especially important here, where the characteristics of water currents in laboratory tanks can greatly impact the feeding ability of suspension feeding organisms (e.g. without the assistance of ambient currents, many of the worm species are predicted to refilter water; Henderson \& Strathmann 2000). Indeed, bryozoans grow more slowly in laboratory tanks than in their natural environment (Henderson 2001). Therefore, to confirm that the symbiotic interaction in nature provides a significant growth benefit to snails of all sizes, I performed field experiments that assessed the proportional growth advantage symbionts gained with respect to suspension feeding snails of the same size.

This symbiotic interaction is alleged to be parasitic, but confirmation of this classification relies on a demonstration that the snail benefits at the expense of its host (Read 1970, Higgins \& Buskirk 1998), which has not previously been tested. Because Trichotropis cancellata steals food but has not been observed directly injuring the host otherwise, I predicted that the snail would negatively impact the host's growth rate.

Pernet \& Kohn (1998) hypothesized that small Trichotropis cancellata are obligate kleptoparasites while large $T$. cancellata are facultative parasites. Theory predicts that suspension feeding is disproportionately energetically more costly for smaller gastropods (Declerck 1995). Although suspension feeding is nearly ubiquitous in feeding veliger larvae, it has never been reported in juveniles that have just settled out of the plankton or hatched from a capsule (Declerck 1995). Creating feeding currents may be relatively more energetically expensive for juveniles than for adults because juvenile gastropods may have: (1) smaller absolute filtering areas than adults; (2) proportionally greater metabolic needs due to faster growth and enhanced activity levels; (3) incomplete development of some feeding organs; or (4) higher hydraulic resistance in the mantle cavity (Declerck 1995). I report in situ experiments designed to assess whether small suspension feeding T. cancellata can grow at all or are, as predicted, obligate symbionts. I also compared the proportional growth advantage parasitism provided over suspension feeding in 3 size classes of snails. I predicted that although all snails associate with worms and benefit from the symbiosis, smaller snails benefit more from the symbiotic interaction than large snails.

The most common situation in the field is for a snail to reside alone on a worm. However, several parasites naturally occur on a single host, and I have found infestations of up to 10 snails (Iyengar 2002). It is unknown if multiple infestations result in competition between the conspecifics. Pernet \& Kohn (1998) reported that a single snail can steal up to $100 \%$ of a worm's food in short-term feeding bouts (1 to $5 \mathrm{~min}$; B. Pernet pers. comm.). Thus, competition among snails on the same worm is likely, and may manifest itself in lower growth rates of competing snails compared with the growth rates of single parasitic snails.

The purposes of the field experiments described in this paper were to determine whether: (1) growth rate is increased for kleptoparasitic compared with suspension feeding Trichotropis cancellata in the 3 size classes; (2) snails on the same Serpula columbiana host compete for food; (3) increased snail growth increases fecundity; and (4) snails reduce the tube growth rate in their host, $S$. columbiana.

\section{MATERIALS AND METHODS}

Study organisms and sampling site. Animal collection and experiments were performed near the Friday Harbor Laboratories (FHL), San Juan Island, Washington. Trichotropis cancellata (snails) and Serpula columbiana (polychaete worms; cf. Serpula vermicularis Linnaeus: see Kupriyanova 1999) are common in the shallow subtidal in this area. Using dredged individuals, Yonge (1962) reported that $T$. cancellata are protandrous hermaphrodites with a 2 yr lifespan - male the first year, female the second year - and females die after spawning. However, the snail lifespan is longer, as medium-sized snails have survived in sea tables on worms for more than $2.5 \mathrm{yr}$, and large snails have survived post-egglaying for at least $1 \mathrm{yr}$ (unpubl. data). Whether snails lay eggs in successive years remains unknown.

Serpula columbiana secretes a permanent calcareous tube that is attached to hard substrata (Fauchald \& Jumars 1979). A tentacular crown catches suspended food particles and translocates them along a ciliated 
groove to the mouth within the tentacular crown. Pernet \& Kohn (1998) demonstrated that $S$. columbiana consume particles that range at least from 40 to $250 \mu \mathrm{m}$.

Experimental racks (snail growth and competition, and worm growth). Snail and worm growth experiments: Single Serpula columbiana on small rocks were collected from Argyle Lagoon and cleaned. I attempted to collect similarly sized worms for use in all experiments. Worm tubes were marked with the fluorescent dye calcein $\left(6.25 \mathrm{~g} \mathrm{l}^{-1}\right.$ in reverse osmosis water, buffered to $\mathrm{pH} 6$ using $\mathrm{NaOH}$ and then diluted to $100 \mathrm{ppm}$ using unfiltered seawater; Moran 2000) through a $48 \mathrm{~h}$ soak in a calcein bath. A distinct permanent yellow ring visible under ambient light formed around the outer edge of the tube. Worms were used in experiments within $1 \mathrm{~d}$ of marking and within $1 \mathrm{wk}$ of field collection.

I collected Trichotropis cancellata from Shady Cove $\left(48^{\circ} 33.94^{\prime} \mathrm{N}, 123^{\circ} 00.39^{\prime} \mathrm{W}\right)$ using SCUBA and sorted the snails into discrete size classes in the laboratory, using only intact shells (complete spire). The length of each $T$. cancellata (from whorl apex to the tip of the siphonal canal; Fig. 1A) was measured to the nearest $0.05 \mathrm{~mm}$ with vernier calipers. The outer apertural lip was marked using nail polish or paint marker. Individual snails were tethered using sewing thread, with one end tied around the penultimate whorl of the shell and the other end attached to a bare rock (suspension-feeder treatment) or near the tube opening of a Serpula columbiana (parasite treatment) (Fig. 1B). Later experiments (Iyengar 2002) yielded the same results as reported here when empty serpulid tubes, rather than plain bare rocks, were used as a suspension-feeding control. Once established on a worm (usually after $1 \mathrm{~d}$ in the laboratory), parasitic snails remained sedentary, stealing food, for long periods of time (see 'Effects of tethering' below).

On 2 June 1998, Trichotropis cancellata were collected and sorted by size. Medium (Med) was 5.4 to $14.0 \mathrm{~mm}$ in length with $90 \%$ between 6.3 and $11.4 \mathrm{~mm}$.
Large (Lg) was 13.1 to $24.2 \mathrm{~mm}$ in length with $90 \%$ between 14.1 and $20 \mathrm{~mm}$. In the discussion that follows, treatments are various combinations of snails and worms, and a replicate is one of those snail-worm combinations, so that treatments vary in the number of snails and worms contained in each replicate. Treatments are coded by indicating whether the snails were parasites or suspension feeders, then indicating the size of each snail in the treatment after a hyphen (e.g. S-Sm indicates 1 small suspension feeding snail P-LgMed indicates a large and a medium snail tethered on the same worm and allowed to parasitize).

To determine whether snails grow more in $5 \mathrm{wk}$ as parasites than as suspension feeders, whether snails on the same host compete, whether smaller snails benefit proportionally more from parasitism than larger snails, and whether parasites reduce host growth, I constructed the following 9 treatments (30 replicates each unless noted otherwise): P-Med; P-MedMed; P-MedMedMed; P-Lg; P-LgLg; P-LgMed; S-Med (15 replicates); S-Lg (15 replicates); and Unpara (unparasitized Serpula columbiana). Each rack was a $20.5 \times 35.5 \mathrm{~cm}$ Plexiglas sheet. Loops of latex surgical tubing held 16 rocks to the racks. Two replicates of each treatment were randomly interspersed on each rack, with 15 racks total. Each rack was attached to a horizontal concrete block at $18 \mathrm{~m}$ depth at Shady Cove. These racks were deployed on 6 June 1998 and left for 29 d (to 5 July 1998). Both Trichotropis cancellata and S. columbiana naturally occur in the area used for the experiments.

During experiments, racks were checked weekly in situ to ensure that treatments were still intact. Any replicate that, for more than $1 \mathrm{wk}$, did not adhere to its assigned treatment (either because snails left their worms or disappeared) was discarded from the analysis. If a replicate adhered to a treatment other than the one it was assigned for all but $1 \mathrm{wk}$, it was considered as another replicate of the new configuration. For
Fig. 1. Trichotropis cancellata. (A) Empty shell demonstrating length measurement. (B) Close-up of a tethered snail (upper middle of picture) established in stealing position on a serpulid

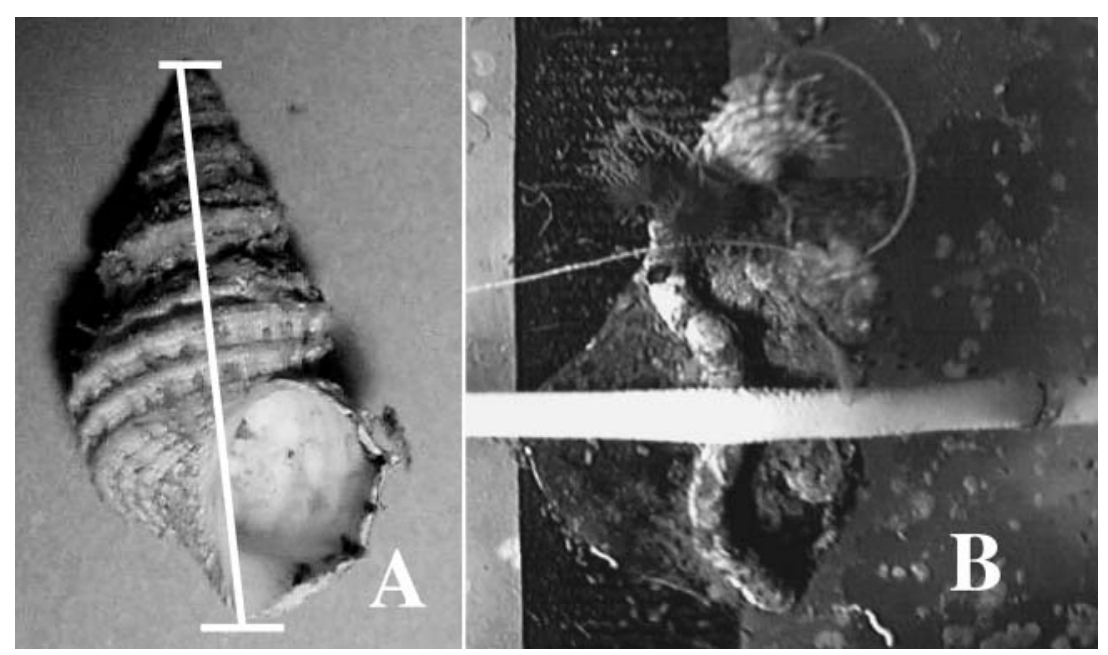


example, if 1 snail in a P-MedMedMed treatment disappeared in Week 1, the remaining snails would be considered a P-MedMed replicate. This change in treatment category happened in less than $15 \%$ of the snails. At the end of the experiment, I brought the racks into the laboratory and measured using an ocular micrometer on a dissecting microscope, the lengths of Trichotropis cancellata shell growth (old apertural lip to new apertural lip, measured in the spiral direction, hereafter referred to as growth) and Serpula columbiana tube growth (from the yellow calcein line to the new tube opening).

In a second experiment, small snails ( $\mathrm{Sm}_{i} 2.0$ to $6.3 \mathrm{~mm}$ in length) were collected in July 1998, marked with nail polish and attached to serpulids or bare rocks, as described above. I also soaked these snails in a $50 \mathrm{mg} \mathrm{ml}^{-1}$ alizarin dye solution for $5 \mathrm{~d}$, staining all pre-existing shell purple as a secondary size-marking method (stock solution $=5 \mathrm{~g} \mathrm{l}^{-1}$ alizarin, stock diluted in sea water; adapted from Day et al. 1995). The 2 treatments (P-Sm and S-Sm) each originally had 16 replicates, interspersed on 2 racks through alternating treatments. A number of these replicates were lost due to mortality during the experiment (see 'Results'). Worm tube growth was not measured in this experiment. Racks were deployed on 15 July 1998 and retrieved on 7 August 1998. Snail growth was measured as outlined above.

Data analysis: All statistical analyses were performed using the statistical program DataDesk (Velleman 1988). The snail growth results were analyzed using a 1-way ANCOVA for treatment effect on snail growth, using rack as a random blocking factor (dropped if not significant) and initial snail length as a covariate (dropped for Sm snail comparisons due to lack of significance). A ln $(y+1)$ data transformation was used on the Med and Lg snail growth data to meet model assumptions (normal distribution, homogeneity of variance; verified through analysis of residuals). Growth of parasitic snails was compared with growth of the appropriately sized suspension feeding snails. In multiple snail treatments, average snail growth was compared with that of the same sized single snail treatment. All snail growth pairwise comparisons used Bonferroni post hoc tests, adjusting individual $\alpha$ levels to create a family level $\alpha=0.05$.

Linear regression tested for competition effects by evaluating the relationship between snail growth and number of conspecifics on the same worm host for small and large snails. Competition among conspecifics on the same host could result in either: (1) all snails growing less (equal competitors); or (2) 1 snail growing as if alone on the worm and the others growing as if they were suspension feeders (superior and inferior competitors, respectively). If all snails are equal competi- tors, the variances of the single parasite treatment and the multiple parasite treatments should be approximately equal; whereas if there is a superior competitor, the multiple parasite treatment should have a greater variance. The nonparametric Moses test (Daniel 1978) was used to test for equal dispersion among the groups.

The worm tube growth results were analyzed using a 1-way ANOVA for treatment effect on worm growth rate, with rack as a random blocking factor (dropped if not significant). Analysis of residuals verified that the data met model assumptions. The growth rate of parasitized worms was compared with that of unparasitized worms using Bonferroni post hoc tests. Because of the large number of simultaneous pairwise comparisons, individual $\alpha$ level was restricted to $<0.005$ to avoid missing any real effects, so the family $\alpha$ level was $>0.05$ (a trade-off between Type I and Type II error). Linear regression tested whether increasing numbers of medium-sized and large parasites resulted in increasingly detrimental effects on worm tube growth rates.

Morphometric measurements: If suspension feeding is disproportionately costly for smaller gastropods (Declerck 1995), shifting to parasitism should provide comparatively greater benefits to smaller Trichotropis cancellata than larger snails. Because Sm snail experiments were performed 1 mo after those using Med and Lg snails, snail growth was compared only between Med and Lg snail treatments. Within the same size class, the parasitic snails' average amount of shell growth was divided by the suspension feeding snails' average amount of shell growth. This value estimates the proportional growth increase of kleptoparasitism over suspension feeding for each size class. The proportional benefit was then compared between Med and Lg snails to determine which size class profited more from parasitism.

Linear growth must be transformed to determine volume added. The shape of a snail can be described as a cone wrapped around a vertical axis of rotation. In Trichotropis cancellata, for growth increments much less than a whorl, the rate of expansion of the cylinder is small; hence, the volume added here is approximated by a cylinder. The radius of the cylinder is equal to the radius of the aperture $(R)$, the height $(H)$ of the cylinder is equal to the growth increment measured in the field experiments (distance from old to new shell apertural lip) and the volume of the cylinder $(V)$ is described by the equation:

$$
V=\pi R^{2} H
$$

In a measured sample of Trichotropis cancellata, snail length $(X)$ between 8.73 and $32.1 \mathrm{~mm}$ (unpubl. data) was significantly correlated $\left(\mathrm{r}^{2}=0.886, \mathrm{n}=149\right.$, $\mathrm{p}<0.01$ ) with the width of the shell at the last whorl $(Y)$ through the equation: 


$$
Y=1.15 X^{0.761}
$$

Because Trichotropis cancellata has no umbilicus, I can assume that

$$
Y \cong 4 R
$$

Eq. (3) underestimates $Y$, but the small difference should not be great enough to affect my results. Using the average of the initial and final lengths of each experimental snail (which differed by less than $2 \mathrm{~mm}$ in $>85 \%$ of the snails) as $X$ in Eq. (2), I obtained $Y$ for each snail. I then used Eq. (3) followed by Eq. (1) to calculate $V$, the volume grown by each snail during the experiment. The average volume gained was compared between medium-sized and large snails.

Effect of prior feeding mode on the growth of suspension feeding snails. Snails in the field may segregate based on suspension feeding ability, with the more efficient suspension feeders remaining free-living and the less efficient suspension feeders found only as parasites. To investigate this possibility, the growth rates of snails restricted to suspension feeding was compared among snails collected from non-host substrata $(n=9)$ and those collected from living serpulid worm tubes (originally $\mathrm{n}=8$ but 3 replicates were lost during the experiment). Snails were collected, marked, deployed and measured as described above, but were tethered directly to the experimental rack rather than to rocks. This experiment was deployed and ran concurrent with the first experiment listed above (6 June to 5 July 1998). Because sample sizes were small, I performed a power analysis after statistical comparisons, using the UCLA statistics department's computer program (http://ebook. stat.ucla.edu/calculators/powercalc/). Statistical power $(1-\beta)$ is the likelihood that a test will detect true differences between treatments and ideally should have a value greater than 0.8 .

Fecundity benefit for larger snails. Foraging theories assume that animals foraging optimally have higher fitness than individuals that do not, but this assumption is seldom directly tested (Jaeger \& Lucas 1989). For kleptoparasitism to be selectively advantageous over suspension feeding, any differential growth demonstrated above must have an effect on fecundity. Ovipositing Trichotropis cancellata lay up to 26 round flat capsules in a planispiral arrangement (Yonge 1962) and remain on the mass until the young hatch as veligers (at least $5 \mathrm{wk}_{\text {; }}$ pers. obs.). Therefore, clutches are easily collected and maternity determined. Because maternal tending involves long periods of time and few untended egg masses are found in the field (pers. obs.), it is assumed that females lay only 1 egg mass per season.

Snails could not be maintained on experimental racks long enough for mating and egg laying, due to severe mortality of snails and worms caused by crabs. Instead, the relationship between snail size and the number of offspring produced was assessed using gravid snails from the field. In late January 2000, over 200 snails were collected from the field and allowed to lay eggs in the laboratory. Snails tending egg capsules in the field were not collected. Egg masses were censused when individual veligers were observed within the egg capsules (approximately $3 \mathrm{wk}$ post-deposition) by opening each capsule and counting the total number of veligers. Linear regression was used to determine the increase in the number of veligers produced with an increase in maternal size (length from the whorl apex to the tip of the siphonal canal).

Effects of tethering. To determine whether the results of the growth experiments were skewed by the tethering procedure, I performed a similar experiment using untethered snails. Snails were separated into 2 size classes $(\mathrm{Med}=6.1$ to $10.25 \mathrm{~mm} ; \mathrm{Lg}=12.6$ to $20.7 \mathrm{~mm}$ ) and each size class was divided among 2 treatments: bare rock or worm host $(n=5$ per size class $\times$ treatment combination). Snails (dyed and marked as described above) were placed individually in plastic freezer containers $(8 \times 8 \times 13$ or $9 \times 9 \times 9.5 \mathrm{~cm})$ with mesh sides (1000 $\mu \mathrm{m}$ mesh) and either a bare rock or a rock with a Serpula columbiana. These containers were held in a large mesh basket suspended from the dock at FHL, arranged to alternate treatments in the basket. After 2.5 wk (13 to 30 June 1998), total snail growth was measured. Snails were again dyed using alizarin, the new apertural lip was marked with nail polish, and the snails were placed in the opposite treatment and suspended from the dock (on 2 July 1998). The experiment ended on 3 August 1998. Data were analyzed using a 1 -factor ANOVA with treatment as the fixed effect and $\ln ($ growth +1$) \mathrm{mm}$ as the dependent variable.

To assess the degree to which tethering disturbs the snails' normal behavior, 32 untethered Trichotropis cancellata individuals were numbered by attaching bee tags (plastic discs $2 \mathrm{~mm}$ in diameter; Christian Glaze KG) to their shells. The snails were then allowed to establish themselves on Serpula columbiana, with the restriction that only 1 snail was allowed per host. After $1.5 \mathrm{~d}$ in the laboratory, 32 S. columbiana, each parasitized by a single, numbered snail, were placed on 2 racks (similar to those described above) and deployed subtidally at Shady Cove. Divers recorded the position of each snail on the racks at approximately weekly intervals from 25 June to 18 August 1998 and then for a final time on 16 March 1999.

\section{RESULTS}

\section{Snail growth and competition}

The growth rates of snails collected from worms and those collected from non-host substrata did not differ 
significantly when both groups were restricted to suspension feeding $(F=0.036, \mathrm{df}=1, \mathrm{p}>0.5)$. The mean growth rate $( \pm \mathrm{SE})$ of snails collected from worms $(n=5)$ was $0.017 \pm 0.002 \mathrm{~mm} \mathrm{~d}^{-1}$, while that of snails collected from non-host substrata ( $\mathrm{n}=9$ ) was $0.022 \pm 0.003 \mathrm{~mm}$ $\mathrm{d}^{-1}$. A power analysis determined that for an $\alpha<0.1$, my results had a power level $(1-\beta)$ of only 0.51 . Thus, the conclusion that prior feeding mode has no bearing on the future growth rates of suspension feeding snails must be tentative. Therefore, only snails from worm hosts were used in the following growth experiments.

Tethered alone, parasitic Trichotropis cancellata in all 3 size classes grew significantly more quickly than suspension feeders in the same size class (Fig. 2A; $\mathrm{p}<0.05$, after Bonferroni adjustments). P-MedMed and P-MedMedMed snails (Fig. 2B) grew significantly more quickly than S-Med (Fig. 2A; $p<0.001$ ), but significantly more slowly than P-Med (Fig. 2B; $\mathrm{p}<0.05$ ). P-LgLg snails grew at a rate that was not significantly different from either S-Lg $(p>0.1)$ or P-Lg $(p>0.5)$. Med snails of the P-LgMed treatment grew significantly more slowly than P-Med $(\mathrm{p}<0.01)$, P-MedMed $(\mathrm{p}<0.01)$ or P-MedMedMed snails $(\mathrm{p}<0.05)$, but more quickly than $\mathrm{S}-\mathrm{Med}$ snails $(\mathrm{p}<0.05)$. Lg snails of P-LgMed grew at a rate that was not significantly different from the S-Lg $(p>0.1)$ and P-Lg snails ( $p>0.5)$.

Linear regression showed that for Med snails there was a significant negative relationship between the number of parasitic snails on a host and snail growth rate (Fig. $2 \mathrm{~B}_{;} \mathrm{r}^{2}=0.23, \mathrm{n}=96, \mathrm{p}<0.005$ ). These data support the hypothesis of competition among Med snails for a limited resource-the amount of food a worm can procure per unit time. Using the Moses test, the null hypothesis of equal variance could not be rejected when comparing the dispersion of data in the P-Med and P-MedMed treatments $(0.05<\mathrm{p}<0.1)$, nor when comparing the P-Med and P-MedMedMed treatments $(p>0.1)$. Thus, there is no superior snail competitor when Med snails share a host. The growth rate of P-Lg snails was not significantly different from that of P-LgLg (Fig. 2B), suggesting that they are affected less by competitors than are Med snails.

This leads us to the question: is parasitism more important to smaller snails? Parasitic snails of all sizes grew more quickly than suspension feeding snails. When considering the comparative benefit of kleptoparasitism among size classes, the amount of new volume gained, in addition to the linear measurement of the length of new shell growth, should be considered. S-Med snails gained only $1 / 3$ as much volume as S-Lg, despite growing more than S-Lg in a 2-dimensional growth measurement (Table 1; distance to new apertural lip). However, P-Med snails gained $144 \%$ as much volume as did P-Lg (Table 1). This result suggests that kleptoparasitism provides a proportionally
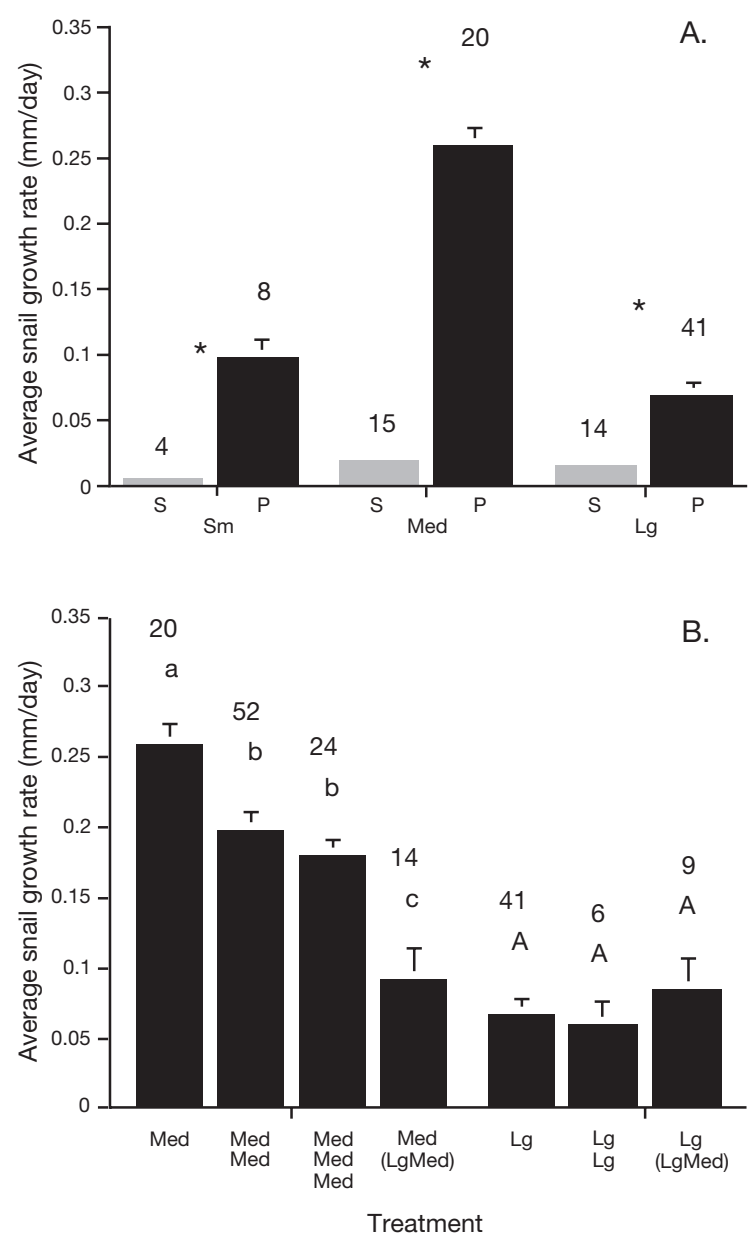

Fig. 2. Trichotropis cancellata on Serpula columbiana. Average growth rate $(+\mathrm{SE})$ of snails in rack experiments. Numbers above the bars indicate the number of replicates. There was a significant effect of treatment in both the experiment involving Med and $\mathrm{Lg}$ snails (ANCOVA, $F=28.1, \mathrm{df}=8, \mathrm{p}<0.0001$ ) and the experiment involving $\mathrm{Sm}$ snails $(\mathrm{ANCOVA}, F=21.3$, df $=1$, $\mathrm{p}<0.005)$. Note that $\mathrm{Sm}$ treatments were run 1 mo after the others. (A) Average growth of suspension feeding (S) and parasitic (P) snails in each of the 3 snail size classes $(\mathrm{Sm}=$ small, 2.0 to $6.3 \mathrm{~mm}$ length; $\mathrm{Med}=$ medium, 5.4 to $14.0 \mathrm{~mm}$ length; $\mathrm{Lg}=$ large, 13.1 to $24.2 \mathrm{~mm}$ length). Bars are grouped in sets that were compared in statistical tests. *Bonferroni-adjusted LSD pairwise comparisons that were statistically different $(p<0.05)$. (B) Effect of competition on the average growth of parasitic snails. Letters represent treatments that were significantly different using Bonferroni-adjusted LSD pairwise comparisons; different cases of letters indicate different comparisons (because treatments were only compared within the same size class). LgMed indicates the treatment with 1 large and 1 medium snail. The growth of each size class in the LgMed treatment is plotted separately

greater growth benefit over suspension feeding for Med snails than for Lg snails. Indeed, when examining the percent increase of kleptoparasitism compared with suspension feeding, there is a trend of increasing benefit with decreasing snail size in both linear and volumetric measurements (Table 1). 
Lg snails in the P-LgMed treatment grew more (linearly and volumetrically) than snails in the P-Lg treatment, while Med snails in the P-LgMed treatment grew even less than snails in the P-MedMedMed treatment. This finding suggests that the Lg snails in the P-LgMed treatment benefited at the expense of the smaller snails.

\section{Experimental racks: serpulid worm growth}

Unparasitized serpulids grew significantly more quickly than all parasitized worms during 1 mo (Fig. 3). Worms parasitized by a Lg snail grew significantly more slowly than worms parasitized by a Med snail $(p<0.05)$, but at a rate that was not significantly different from those parasitized by -MedMed $(p>0.2)$ or -MedMedMed snails ( $p>0.2)$. A negative linear regression between the number of Med snail parasites and host worm tube growth was significant $\left(\mathrm{r}^{2}=0.19, \mathrm{n}=\right.$ 55, $\mathrm{p}<0.01$ ). However, for $\mathrm{Lg}$ parasites, the regression between number of parasites and worm tube growth was not significant $\left(\mathrm{r}^{2}=0.03, \mathrm{n}=44, \mathrm{p}>0.5\right)$ and tube growth rate was similar among these treatments.

\section{Fecundity benefit}

A positive linear regression between the length of snails and the number of veligers produced was significant (Fig. 4; $\mathrm{r}^{2}=0.64, \mathrm{n}=60, \mathrm{p}<0.0001$ ).

\section{Effects of tethering}

To ensure that the results of the growth rate experiment described above were not artifacts of the tethering procedure, similar experiments were used to measure

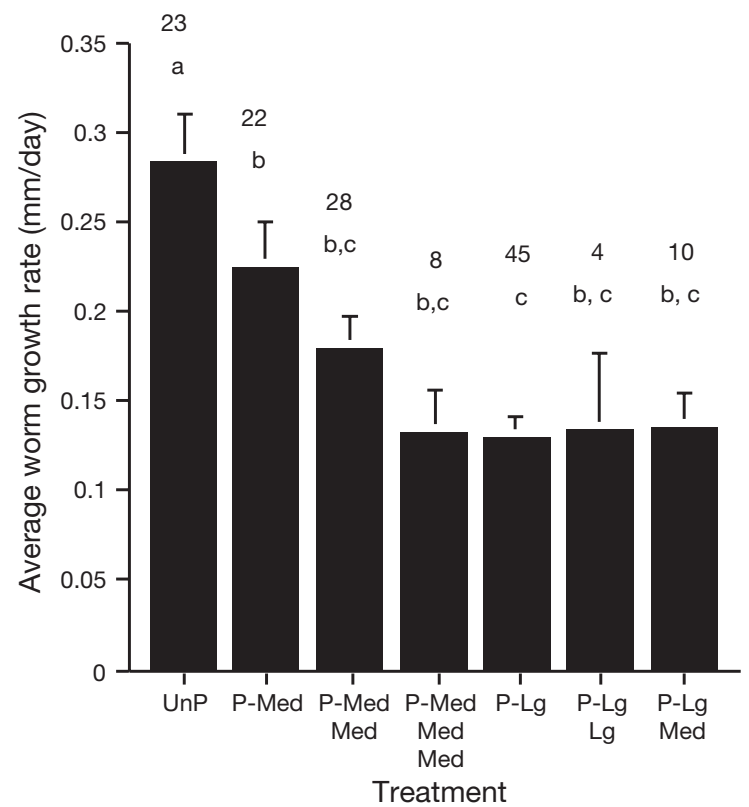

Fig. 3. Serpula columbiana parasitized by Trichotropis cancellata. Average growth rate (+ SE) of serpulid worms either unparasitized (UnP), or parasitized (P-) with 1, 2 or 3 medium snails (-Med,-MedMed, -MedMedMed, respectively), or 1 or 2 large snails (-Lg, $-\mathrm{LgLg}$, respectively), or with 1 medium and 1 large snail (-LgMed). Numbers above the bars indicate the number of replicates. Worm tube growth varied significantly among treatments (ANOVA, $F=9.9$, df $=6, \mathrm{p}<0.0001$ ). Different letters represent treatments that were significantly different using Bonferroni-adjusted LSD pairwise comparisons $(p<0.05)$

the growth rates of untethered medium-sized and large snails. In both halves of the experiment (early and late summer), there was a significant effect of treatment (1-factor ANOVA: in early summer, $\mathrm{df}=3, F=3.83, \mathrm{p}<$ 0.05 ; in late summer, $\mathrm{df}=3, F=52.13, \mathrm{p}<0.0001$ ). In pairwise comparisons, P-Med snails grew significantly more quickly $(p<0.05)$ than S-Med snails in both the early and

Table 1. Trichotropis cancellata on Serpula columbiana. Horizontal shell growth and volume gained by each of the treatments in the growth rate experiment. Snails were parasites (P-) or suspension feeders (S-) and large (Lg; 13.1 to $24.2 \mathrm{~mm}$ length) or medium (Med; 5.4 to $14.0 \mathrm{~mm}$ length). The number of snails of a particular size present on the same host in a treatment is indicated by repetition of the size category in the treatment label (e.g. P-LgLg indicates 2 large snails on a worm). Sm treatments were run 1 mo after the others

\begin{tabular}{|c|c|c|c|c|c|c|c|}
\hline Treatment & $\begin{array}{l}\text { Sample } \\
\text { size (n) }\end{array}$ & \multicolumn{2}{|c|}{ Shell growth (mm) } & $\begin{array}{l}\text { Growth benefit over same- } \\
\text { sized suspension feeder (\%) }\end{array}$ & \multicolumn{2}{|c|}{$\begin{array}{l}\text { Volume gain }\left(\mathrm{mm}^{3}\right) \\
\text { Mean } \mathrm{SE}\end{array}$} & $\begin{array}{l}\text { Volume increase over same- } \\
\text { sized suspension feeder }(\%)\end{array}$ \\
\hline $\mathrm{S}-\mathrm{Sm}$ & 4 & 0.14 & 0.06 & - & 0.3 & 0.2 & - \\
\hline P-Sm & 8 & 2.32 & 0.33 & 1657 & 5.1 & 1.1 & 1853 \\
\hline S-Med & 15 & 0.57 & 0.16 & - & 3.3 & 0.9 & - \\
\hline P-Med & 20 & 7.76 & 0.43 & 1361 & 53.0 & 4.4 & 1615 \\
\hline P-MedMed & 52 & 5.97 & 0.37 & 1047 & 36.0 & 2.7 & 1095 \\
\hline P-MedMedMed & 24 & 5.39 & 0.35 & 946 & 35.4 & 3.6 & 1079 \\
\hline P-LgMed (Med) & 14 & 2.76 & 0.63 & 484 & 15.4 & 3.8 & 469 \\
\hline S-Lg & 14 & 0.42 & 0.14 & - & 9.6 & 3.7 & - \\
\hline P-Lg & 41 & 2.03 & 0.29 & 483 & 36.8 & 5.5 & 384 \\
\hline P-LgLg & 6 & 1.81 & 0.49 & 431 & 28.0 & 7.7 & 293 \\
\hline P-LgMed (Lg) & 9 & 2.57 & 0.61 & 612 & 45.9 & 10.6 & 1256 \\
\hline
\end{tabular}




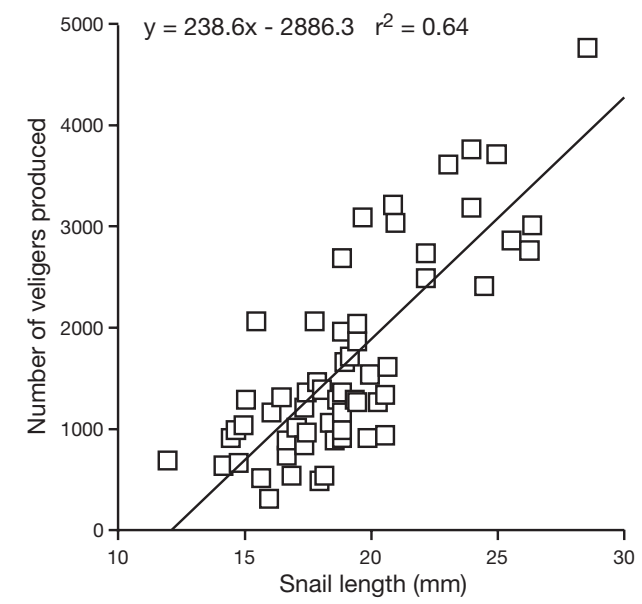

Fig. 4. Trichotropis cancellata. Correlation between size of snail and number of veligers produced (Model 1 linear regression). The equation represents the best-fit line through the data

late summer. In the early summer, the growth rate of P-Med was $0.097 \pm 0.028 \mathrm{~mm} \mathrm{~d}^{-1}$ (mean $\pm \mathrm{SE}$ ) and that of S-Med was $0.030 \pm 0.014 \mathrm{~mm} \mathrm{~d}^{-1}$. In the late summer, the growth rate of P-Med was $0.114 \pm 0.021 \mathrm{~mm} \mathrm{~d}^{-1}$, while that of S-Med was $0.006 \pm 0.002 \mathrm{~mm} \mathrm{~d}^{-1}$. Alternatively, in pairwise comparisons, P-Lg snails grew at rates that were not significantly different from those of S-Lg snails $(p>0.2)$. In the early summer, the growth rate of P-Lg was $0.041 \pm 0.010 \mathrm{~mm} \mathrm{~d}^{-1}$ and that of S-Lg was $0.016 \pm$ $0.004 \mathrm{~mm} \mathrm{~d}^{-1}$. In the late summer, the growth rate of P-Lg was $0.012 \pm 0.004 \mathrm{~mm} \mathrm{~d}^{-1}$, while that of S-Lg was $0.009 \pm$ $0.002 \mathrm{~mm} \mathrm{~d}^{-1}$. Thus, at least for Med snails, the results of the experimental racks described above were not tethering artifacts. The small number of replicates $(n=5$ for each treatment) probably obscured a small difference in the growth rates of parasitic and suspension feeding Lg snails. I conclude that the results of the experiments using untethered snails are consistent with the results of the tethered snail experiments.

In racks deployed subtidally with numbered but untethered snails, little movement was observed. After 7 wk, 13 snails had not moved at all, 16 snails had changed hosts within the same rack and 3 snails had disappeared from the racks. Therefore, it is unlikely that tethering substantially alters a snail's behavior. Once a snail establishes itself on a host, it remains on or near the host for long periods of time.

\section{DISCUSSION}

\section{Degree of benefits of parasitism depend on snail size and conspecifics}

Trichotropis cancellata perform kleptoparasitism to obtain additional resources. During $1 \mathrm{mo}$, parasitic snails can grow up to 16 times more quickly in a linear dimension and gain up to 18 times more volume than suspension feeding snails of the same size. The pattern first quantified by Pernet \& Kohn (1998) in the laboratory occurs in nature: parasitic $T$. cancellata of all sizes grow significantly more quickly than suspension feeding $T$. cancellata. Parasitism provides a larger benefit to smaller snails than to larger ones. As suspension feeders, medium-sized snails add body volume at approximately $1 / 3$ of the rate of large snails, but as parasites, mediumsized snails add body volume at almost 1.5 times the rate of large snails. For both linear and volumetric measurements, the growth benefit incurred through the switch from suspension feeding to kleptoparasitism tends to increase with decreasing snail size. Similarly sized hosts were used among different sized snail treatments, so host size was likely not responsible for this trend. Thus, I conclude that smaller snails gain a larger growth benefit from kleptoparasitism. These findings are consistent with Declerck's hypothesis (1995) that suspension feeding is less rewarding for smaller gastropods; conversely, kleptoparasitism may be disproportionately more effective for smaller snails.

Because individual snails steal a large proportion of their host's food (up to $100 \%$ in short-term feeding bouts of 1 to 5 min; Pernet \& Kohn 1998, B. Pernet pers. comm.), I predicted that multiple snails on the same worm compete for the limited food resource. There was a significant negative relationship between snail growth rate and the number of medium-sized snails parasitizing a single Serpula columbiana host. The same relationship was not detectable among large snails. This difference suggests that large snails are less affected by competition for food. The benefit of a worm to a snail is significant, as even parasites in infections of 3 medium-sized snails grew more quickly than suspension feeding snails. However, this benefit is limited by the amount of food a worm can capture, a limitation large snails can offset. Based on the Moses test, all medium-sized snails in the multiple infection treatments grew more slowly than single medium-sized parasites. Thus, all medium co-parasitic snails obtain approximately equal shares of the host's food; there was not a superior competitor among medium snails.

Competition can be classified in 1 of 2 forms: interference competition (the competitors interact directly) or exploitation competition (the competitors exert indirect inhibitory effects on each other) (Pianka 1974). Two Trichotropis cancellata can steal food from a worm's mouth at the same time, but snails never attempt to dislodge each other's pseudoproboscides (pers. obs.). The apparent lack of intraspecific aggression, coupled with the reduced growth rates of all competing snails, suggest that $T$. cancellata engages in exploitation, rather than interference competition. 
Pernet \& Kohn (1998) proposed that small snails cannot meet their basic metabolic needs solely by suspension feeding and thus are obligate parasites. This situation may be true in areas of low food concentrations, as can occur in laboratory sea tables, the environment of Pernet \& Kohn's (1998) experiments. However, small suspension feeding snails in experimental racks in the field did grow, albeit very slowly. Thus, Trichotropis cancellata of all size classes remain facultative, rather than obligate, parasites.

Snails collected from non-host substrata and those collected from worm hosts grew at the same rate when forced to suspension feed. Although the results are tentative, I conclude that the snails do not segregate into separate subpopulations, one always on hosts and one never on hosts, based on differences in suspension feeding ability. Feeding mode is not a dichotomous trait in Trichotropis cancellata. Snails on the non-worm substrata may be merely moving between or searching for hosts.

\section{Benefits of faster snail growth}

The strong correlation between female snail size and fecundity in Trichotropis cancellata suggests that parasitism results in significantly more offspring and should, therefore, confer an evolutionary advantage. If larger males produce more sperm and become larger females ( $T$. cancellata is a protandrous hermaphrodite), kleptoparasitism provides fecundity benefits at several life history stages. Larger size enables snails of some species to escape predation through a size refuge (Johannesson 1986, Vermeij 1987, Ash 1989), but this is unlikely in $T$. cancellata because of the large size disparity between this snail and its predators (including the sea star Pycnopodia helianthoides and crabs in the genus Cancer; T. Gage pers. comm., author's unpubl. data).

\section{Effects on the serpulid worm host}

Trichotropis cancellata is a true parasite (sensu Read 1970, Higgins \& Buskirk 1998); the snails profit at the expense of the worms. Anderson \& May (1978) argue that a 'true' parasite must have a detrimental effect on the intrinsic growth rate of its host population. Whether a direct correlation exists between serpulid tube growth and fecundity is unknown, but it is reasonable to expect that tube growth has a selective value. Tube growth generally moves food collecting host radioles further from the reduced water velocity of the boundary layer and the tube is the worm's greatest protection against predators. I interpret slower tube growth as an indicator of a worm's general physiological stress.

Higgins \& Buskirk (1997) showed that the impact of spider-web kleptoparasites depends on the number of parasites present. Similarly, in my experiments with medium-sized snails, the tube growth rate of Serpula columbiana worms decreased significantly with an increasing number of parasites. However, a similar trend did not exist in experiments with large snails. One large parasitic snail may reduce a worm host to its minimum rate of tube extension, so that additional kleptoparasites do not further reduce the host's growth rate. It remains unknown whether additional large kleptoparasites reduce the tissue growth of the worms despite a lack of effect on the rate of tube extension.

Despite a decrease in tube growth, the Trichotropis cancellata-serpulid interaction could be categorized as mutualism if the worms benefit in ways other than growth, such as a reduced level of predation due to the snail's presence. However, this is not the case. Snails are unlikely to deter crab predators, which crack the worm's tube in the middle and would not be deterred by a snail at the worm tube opening (B. Pernet \& author's pers. obs.). Preliminary observations of sculpins attempting to feed on a serpulid's tentacular crown (pers. obs.) indicate that fish appear likewise undeterred by the presence of a snail. Thus, the snail and worm symbiosis can be classified as a parasitic interaction, with no benefit to the polychaete host.

As a caveat, Trichotropis cancellata does not always reduce the tube growth of its serpulid host. In 2 of 4 experiments not previously mentioned in this paper but of similar design as those described herein, tube growth of parasitized serpulids was not significantly slower than that of unparasitized serpulids ( $\mathrm{n}<29$ in 1 experiment, B. Pernet and author's unpubl. data; $\mathrm{n}<$ 15 in the other, unpubl. data). Both experiments showing aberrant serpulid tube growth were performed at the end of summer 1998 and had significant rack effects not present in any other experiment. Thus, differences in microhabitat may have contributed to these aberrant results. I conclude that the interaction between $T$. cancellata and serpulid worms usually, but not always, causes a decrease in host tube growth and thus, can be considered a parasitic symbiosis.

\section{Impact of this interaction and future directions}

Symbiotic interactions (commensalism, mutualism and parasitism) are common in many habitats and often have immense biological consequences (Douglas 1994). However, few studies can examine the costs and benefits of symbiosis to both partners, as symbionts are often obligate and cannot live outside the association. 
Facultative parasitic interactions, as in Trichotropis cancellata and its hosts, can provide critical insight into the evolution and modern mechanisms of symbiosis. Experiments can assess the performance of each symbiont within (as kleptoparasites) and outside (as independent feeders) the interaction, and determine the comparative benefits of each feeding mode.

Even in well-studied avian and arachnid systems, the effects of kleptoparasitism on the participants are rarely directly quantified through comparisons of kleptoparasitic individuals and those living independently (Elgar 1993). This system provides important insight into not only the evolution of parasitism and the mechanics of symbioses, but also the selection pressures faced by suspension feeding snails. Although more data are needed, the present results demonstrate that suspension feeding Trichotropis cancellata are food limited. After switching to parasitism, snails grow faster, regardless of their size. Elucidating the physical parameters limiting the suspension feeding abilities of T. cancellata and comparing these traits to similar ones in bivalves may allow us to determine some of the general characteristics that have forestalled expansive evolutionary radiation of suspension feeding in gastropods.

Acknowledgements. I thank K. Britton-Simmons, J. Kido and E. Pueschel for research assistance. B. Pernet helped design the tethering experiments, D. Duggins provided longitude and latitude data for Shady Cove, and W. Allmon, A. Kohn, D. Padilla and B. Pernet provided helpful advice. This manuscript benefited from reviews by W. Allmon, A. Graham, N. Hairston, C. D. Harvell, J. Morin, B. Pernet, K. Teusch and 4 anonymous reviewers. I thank the director and staff of the Friday Harbor Laboratories for facilities and support. This research was supported by a National Science Foundation Predoctoral fellowship, the Conchologists of America, Sigma Xi (Cornell Chapter), and Cornell University research grants.

\section{LITERATURE CITED}

Anderson RM, May RM (1978) Regulation and stability of host-parasite population Interactions. Part 1. Regulatory processes. J Anim Ecol 47:219-248

Ash VB (1989) Resistance to shell breaking in two intertidal snails. Zool J Linn Soc 96:167-184

Daniel WW (1978) Applied nonparametric statistics. Houghton Mifflin Company, Boston

Editorial responsibility: Otto Kinne (Editor),

Oldendorf/Luhe, Germany
Day RW, Williams MC, Hawkes GP (1995) A comparison of fluorochromes for marking abalone shells. Mar Freshw Res 46:599-606

Declerck CH (1995) The evolution of suspension feeding in gastropods. Biol Rev Camb Phil Soc 70:549-569

Douglas AE (1994) Symbiotic interactions. Oxford University Press, Oxford

Elgar MA (1993) Inter-specific associations involving spiders: kleptoparasitism, mimicry and mutualism. Mem Qld Mus 33:411-430

Fauchald K, Jumars PA (1979) The diet of worms: a study of polychaete feeding guilds. Oceanogr Mar Biol Annu Rev $17: 193-284$

Henderson SY (2001) Effects of maternal nutrition on growth form of colonial offspring of a placental bryozoan. $\mathrm{PhD}$ thesis, University of Washington, Seattle

Henderson SY, Strathmann RR (2000) Contrasting scaling of ciliary filters in swimming larvae and sessile adults of fan worms (Annelida: Polychaeta). Invertebr Biol 119:58-66

Higgins LE, Buskirk RE (1998) Spider-web kleptoparasites as a model for studying producer-consumer interactions. Behav Ecol 9:384-387

Iyengar EV (2002) The ecology and evolutionary biology of the marine facultative kleptoparasite Trichotropis cancellata (Mollusca, Gastropoda). PhD thesis, Cornell University, Ithaca

Jaeger RG, Lucas J (1989) On evaluation of foraging strategies through estimates of reproductive success. In: Hughes RN (ed) Behavioral mechanisms of food selection. Springer-Verlag, Berlin, p 83-94

Johannesson B (1986) Shell morphology of Littorina saxatilis Olivi. The relative importance of physical factors and predation. J Exp Mar Biol Ecol 102:183-196

Kupriyanova EK (1999) The taxonomic status of Serpula cf. columbiana Johnson, 1901from the American and Asian coasts of the north Pacific Ocean (Polychaeta: Serpulidae). Ophelia 50:21-34

Moran AL (2000) Calcein as a marker in experimental studies of newly-hatched gastropods. Mar Biol 137:893-898

Pernet B, Kohn AJ (1998) Size-related obligate and facultative parasitism in the marine gastropod Trichotropis cancellata. Biol Bull 195:349-356

Pianka ER (1974) Evolutionary ecology. Harper and Row, New York

Read CP (1970) Parasitism and symbiology. The Ronald Press Company, New York

Timms R, Read AF (1999) What makes a specialist special? Trends Ecol Evol 14:333-334

Velleman PF (1988) DataDesk version 6.0. Statistics guide. Data Description, Ithaca

Vermeij GJ (1987) Evolution and escalation. Princeton University Press, Princeton, New Jersey

Yonge CM (1962) On the biology of the mesogastropod Trichotropis cancellata Hinds, a benthic indicator species. Biol Bull 122:160-181

Submitted: September 24, 2001; Accepted: June 12, 2002

Proofs received from author(s): November 4, 2002 